\title{
Reduction in labor pain by intrathecal midazolam as an adjunct to sufentanil
}

\author{
Alireza Salimi ${ }^{1}$, Reza Amin Nejad ${ }^{1}$, Farhad Safari ${ }^{1}$, Seyed Amir Mohajaerani ${ }^{1}$, Rahim Jahanbakhsh Naghade ${ }^{2}$, \\ and Kamran Mottaghi ${ }^{1}$
}

Department of Anesthesiology, ${ }^{1}$ Loghman Hospital, ${ }^{2}$ Sarem Obstetric Hospital, Tehran, Iran

Background: Anesthesia today has strived to decrease labor pain in a tolerable and controllable fashion. Intrathecal midazolam has been introduced as an adjunct to analgesics. The study was planned to assess the efficacy, safety and duration of analgesia produced by intrathecal midazolam adjunct to sufentanil in decreasing labor pain.

Methods: In a randomized clinical trial 80 parturient included in the study. The two groups were matched for age, cervical dilation, gravid, gestational age, and other demographic characteristics. Combination of sufentanil and midazolam administered intrathecally to experimental group and compared to sufentanil group. Time to reach maximum block, and pain score was measured and recorded.

Results: Groups were matched for age and weight and other demographic characteristic. No significant adverse effect was seen in both groups including decrease in Apgar score. Duration of analgesia was $92.0 \pm 12.7$ in sufentanil group and $185.2 \pm 15.2$ minutes in midazolam and sufentanil group which was significantly different $(\mathrm{P}=0.002)$. Numeric rating scale score was significantly lower in midazolam group compare to sufentanil group at $120 \mathrm{~min}(\mathrm{P}=0.01), 150 \mathrm{~min}(\mathrm{P}=$ $0.0014)$, and $180 \mathrm{~min}(\mathrm{P}=0.001)$.

Conclusions: Intrathecal midazolam as an adjunct to opioid could significantly enhance analgesia in labor pain with no significant adverse effect. Intrathecal injection of midazolam is an appropriate alternative to parenteral or epidural analgesia in small hospital settings. (Korean J Anesthesiol 2014; 66: 204-209)

Key Words: Analgesia, Intrathecal midazolam, Labor pain.

Received: February 21, 2013. Revised: 1st, June 11, 2013; 2nd, July 12, 2013. Accepted: August 29, 2013.

Corresponding author: Kamran Mottaghi, M.D., Department of Anesthesiology, Loghman Hospital, Makhsous St, Kargar Ave, Tehran 1333631151, Iran. Tel: 98-2155424040, Fax: 98-2155424040, E-mail: kmrnmtghi@yahoo.com

(c) This is an open-access article distributed under the terms of the Creative Commons Attribution Non-Commercial License (http:// creativecommons.org/licenses/by-nc/3.0/), which permits unrestricted non-commercial use, distribution, and reproduction in any medium, provided the original work is properly cited. 


\section{Introduction}

Current anesthetic protocols aim to decrease labor pain in a tolerable and controllable fashion with few side effects [1]. The drug of choice in neuraxial anesthesia is debatable because both high quality and an appropriate duration of analgesia without major side effects are required [2]. Intrathecal injection of local anesthetics such as bupivacaine or opioids has been attempted [3], but sustainable and assured analgesia during labor has not been established. Therefore, the duration and effects of analgesics must be enhanced by adding adjuncts. Furthermore, loss of lower limb and pelvic muscle power can affect the bearing-down reflex and result in labor muscle relaxation. Moreover, the recommended doses of opioids have shown variable value in labor pain control in all settings [4].

Intrathecal midazolam as an adjunct to opioids has been shown to be a promising option for decreasing labor pain [5]. It enhances the duration and quality of intrathecal opioidmediated analgesia [6] with no major side effects [7,8]. However, clinicians are disinclined to use midazolam because of a fear of a decreasing Apgar score and severe hemodynamic changes with labor pain [9]. In addition, inconsistent data on neurotoxicity have resulted in reservations in using intrathecal midazolam for labor pain [10]. In this study, we aimed to elucidate the effectiveness of intrathecal midazolam in reducing labor pain and identify any side effects in parturients or infants.

\section{Materials and Methods}

\section{Patient selection}

The study was reviewed and approved by the University Review Board and Hospital Ethics Committee and was performed in accordance with the ethical standards laid down in an appropriate version of the 2000 Declaration of Helsinki (http://www. wma.net/e/policy/b3.htm). Comprehensive information on the trial was provided in both oral and written forms. All parturients and their accompanying adults gave their informed written consent prior to their inclusion in the study according to the University Hospital Ethics Committee.

Inclusion criteria included parturients with the American Society of Anesthesiologists (ASA) physical status of I or II, a full-term single fetus (37-42 week) with a vertex presentation, and normal fetal heart rate. Parturients were excluded from the study if they had contraindications to an intrathecal injection, an allergy to any of the study drugs, significant coexisting systemic or antenatal disease such as preeclampsia or diabetes, and any condition endangering the fetus.

Each parturient was randomly assigned either an even number to receive a combination of intrathecal sufentanil plus preservative-free midazolam (Aburaihan Pharmaceutical Co.) (midazolam group) or an odd number to receive sufentanil alone (control group). Parturients were not stratified by gravidity/parity.

\section{Neuroaxial analgesia}

Administration of intrathecal midazolam and sufentanil were started at a cervical dilation of 4 to $6 \mathrm{~cm}$ based on previous studies [11]. Each parturient was prehydrated with $500 \mathrm{ml}$ of normal saline. Thereafter, the parturient was placed in a sitting position, and intrathecal injection was performed using an 18-G Tuohy epidural needle and 27-G pencil point spinal needle (Portex ${ }^{\circledR}$ CSEcure $^{\mathrm{TM}}$ Combined Spinal Epidural Needle) through lumbar space L3-4. The drugs were diluted in distilled sterile water to a total volume of $4 \mathrm{ml}$ in all cases. Five micrograms of sufentanil and $2 \mathrm{mg}$ of midazolam were used in each parturient regardless of height or weight. After intrathecal injection, the spinal needle was withdrawn, leaving the epidural catheter in place. The parturient was then placed into the supine position with left uterine displacement. The fetus was monitored, and fetal heart rate changes were assessed.

\section{Outcome measurements}

The primary outcome was the duration of analgesia in which the pain score was $<4$. The secondary outcome was the fetus Apgar score and a drop in the mean arterial blood pressure (MAP) in the parturient. Data were collected by a nurse who was unaware of the study groups or drugs. Pain scores were recorded using a $10 \mathrm{~cm}$ numeric rating scale (NRS) $(0=$ no pain, $10=$ worst pain imaginable) immediately before injection and at 30-min intervals after the intrathecal injection until the first request for analgesia. No parturient was sedated during the time used to compare the blocks, analgesia, and pain scores between the groups. The duration of analgesia was defined as the time from the intrathecal injection to the initiation of pain (NRS > 4), at which point the parturient received analgesia (5-15 $\mathrm{ml}$ of $0.1 \%$ bupivacaine and $1-2 \mu \mathrm{g} / \mathrm{ml}$ of sufentanil) through the epidural catheter.

The presence of side effects, including nausea, vomiting, pruritus, and headache, in addition to the arterial blood pressure, heart rate, respiratory rate, Apgar score, and motor blocks, were recorded. Hypotension was defined as a systolic blood pressure of $<100 \mathrm{mmHg}$ or a $20 \%$ decrease from baseline and was treated with a fluid bolus and IV ephedrine, as required. The number of times a parturient vomited was also recorded. In the event of vomiting or the presence of any of these symptoms, the parturient was offered treatment. The presence of back, leg, or buttock pain, in addition to the presence of leg numbness or weakness, 
was assessed. Other symptoms, including urinary incontinence or difficulty emptying the bladder, fecal incontinence, difficulty emptying the bowel, anogenital numbness or burning, and the presence of a headache, were also assessed.

\section{Statistical analysis}

Statistical calculations were conducted using SPS 17.0 (SPSS Inc., Chicago, IL, USA). The demographic and obstetric variables were presented as means \pm SD and were analyzed by Student's $t$-test. Nonparametric variables were measured and analyzed statistically using the chi-square test, Wilcoxon test, and Mann-Whitney test. The NRS scores of the experimental and control groups during the same time period were compared by ANOVA. Multivariate regression analysis was used to compare the effect of midazolam on the NRS score in the control group. $\mathrm{P}<0.05$ was considered to indicate statistical significance. The sample size was estimated using sample size calculator software with a $95 \%$ confidence interval and $\mathrm{P}<0.05$.

Table 1. Demographic and Surgical Characteristics of Parturients

\begin{tabular}{lccc}
\hline & Sufentanil & $\begin{array}{c}\text { Sufentanil }+ \\
\text { Midazolam }\end{array}$ & $\mathrm{P}$ \\
\hline Age (yr) & $27.3 \pm 3.1$ & $27.7 \pm 3.2$ & $0.37^{*}$ \\
Weight (kg) & $80.0 \pm 7.1$ & $77.0 \pm 10.4$ & $0.17^{*}$ \\
ASA I (\%) & 82 & 79 & $0.44^{\dagger}$ \\
Gestational age (mos) & $37.7 \pm 1.6$ & $38.9 \pm 1.2$ & $0.18^{*}$ \\
Cervical dilation (cm) & $4.7 \pm 1.3$ & $4.5 \pm 1.2$ & $0.54^{*}$ \\
Gravid & & & \\
$\quad 1$ & 30 & 31 & $0.42^{\dagger}$ \\
2 & 2 & 9 & $0.68^{\dagger}$ \\
Allergic history (n) & 2 & 2 & $0.50^{\dagger}$ \\
Drug history (n) & $22 \%$ & $28 \%$ & $0.50^{\dagger}$ \\
Habit history (n) & & 2 & $0.29^{\dagger}$ \\
Oxytocin assisted (\%) & & & \\
\hline
\end{tabular}

The data are expressed as means \pm SD (standard deviation). ASA: American Society of Anesthesiologists physical statusclassification system. Significance based on $* t$-test and ${ }^{\dagger}$ chi-squared test.

\section{Results}

\section{Demographic characteristics}

Eighty parturients were recruited, and 40 were assigned to the midazolam and control groups. Group allocation resulted in matched samples, and the groups were not significantly different with respect to age, weight, ASA physical status, gestation age, cervical dilation $(\mathrm{cm})$, or the proportion of parturients in each group who received oxytocin, as determined by the MannWhitney test (Table 1). The gravidity of the parturients was also not significantly different between the two groups by chi-square test $(\mathrm{P}=0.423)$. Histories of habits such as smoking, opium ingestion, or allergies were not significantly different between the two groups $(\mathrm{P}=0.5)$.

\section{Delivery indices and side effects}

The mean Apgar scores at $1 \min (\mathrm{P}=0.42)$ and $5 \min (\mathrm{P}=0.275)$ were not significantly different between the groups (Table 2). There was no difference in the time from intrathecal injection to delivery $(\mathrm{P}=0.13)$ or the rate of cervical dilation $(\mathrm{cm} / \mathrm{h})(\mathrm{P}=0.075)$ (Table 2).

The measured MAP was not significantly different between the groups at any time point $(\mathrm{P}>0.05)$ (Fig. 1). The MAP in both groups at any time point did not change significantly from the baseline value after administration of the drugs $(\mathrm{P}>0.05)$ (Fig. 1).

None of the subjects in either the experimental or control group suffered any numbness, weakness, or leg pain after the procedure. The follow-up time was up to $48 \mathrm{~h}$ postinjection. No patients in the midazolam group experienced nausea or vomiting, while 12 patients (30\%) in the sufentanil-alone group experienced nausea and 3 (7.5\%) experienced vomiting. No other side effects, including urinary incontinence or difficulty emptying the bladder, fecal incontinence or difficulty emptying the bowel, anogenital numbness or burning, or the presence of a headache, were detected.

Table 2. Apgar Scores and Times to Delivery

\begin{tabular}{|c|c|c|c|c|c|}
\hline \multirow{2}{*}{ Apgar score } & \multicolumn{2}{|c|}{ Sufentanil } & \multicolumn{2}{|c|}{ Sufentanil + Midazolam } & \multirow{2}{*}{$\mathrm{P}$} \\
\hline & $1 \mathrm{~min}$ & $5 \mathrm{~min}$ & $1 \mathrm{~min}$ & $5 \mathrm{~min}$ & \\
\hline$<5$ & $2(5 \%)$ & 0 & $1(2.5 \%)$ & 0 & $0.5^{\dagger}$ \\
\hline $5-8$ & $4(10 \%)$ & $3(7.5 \%)$ & $7(17.5 \%)$ & $5(12.5 \%)$ & $0.051^{\dagger}$ \\
\hline$>8$ & $34(85 \%)$ & $37(92.5 \%)$ & $32(80 \%)$ & $35(87.5 \%)$ & $0.54^{\dagger}$ \\
\hline Mean Apgar score & $7.44 \pm 1.14$ & $8.59 \pm 0.54$ & $8.08 \pm 1.36$ & $8.38 \pm 0.97$ & $\mathrm{P}>0.05^{*}$ \\
\hline Time from intrathecal injection to delivery $(\mathrm{h})$ & \multicolumn{2}{|c|}{$4.42 \pm 3.78$} & \multicolumn{2}{|c|}{$4.85 \pm 4.35$} & $0.13^{*}$ \\
\hline Rate of cervical dilation $(\mathrm{cm} / \mathrm{h})$ & \multicolumn{2}{|c|}{$1.20 \pm 0.92$} & \multicolumn{2}{|c|}{$1.32 \pm 0.87$} & $0.075^{*}$ \\
\hline
\end{tabular}

The data are expressed as means \pm SD. h: hour. Significance based on $* t$-test and ${ }^{\dagger}$ chi-squared test. 
A

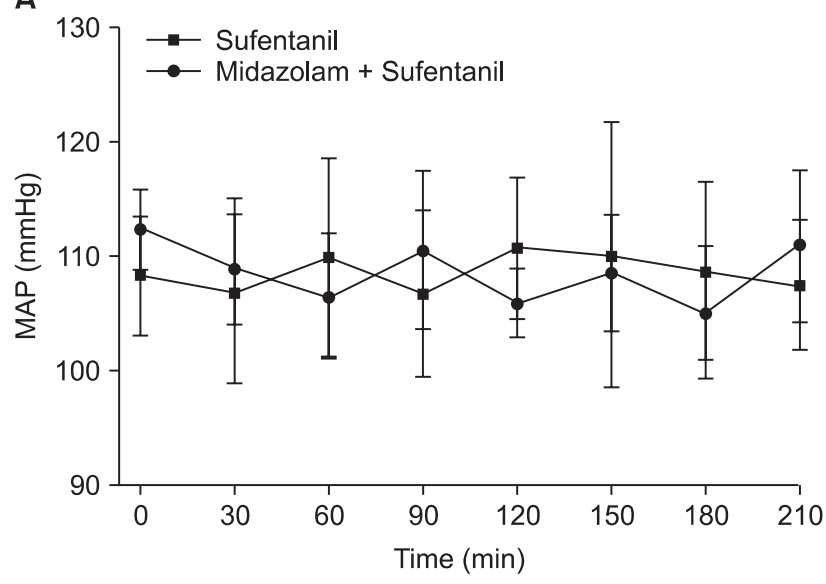

B

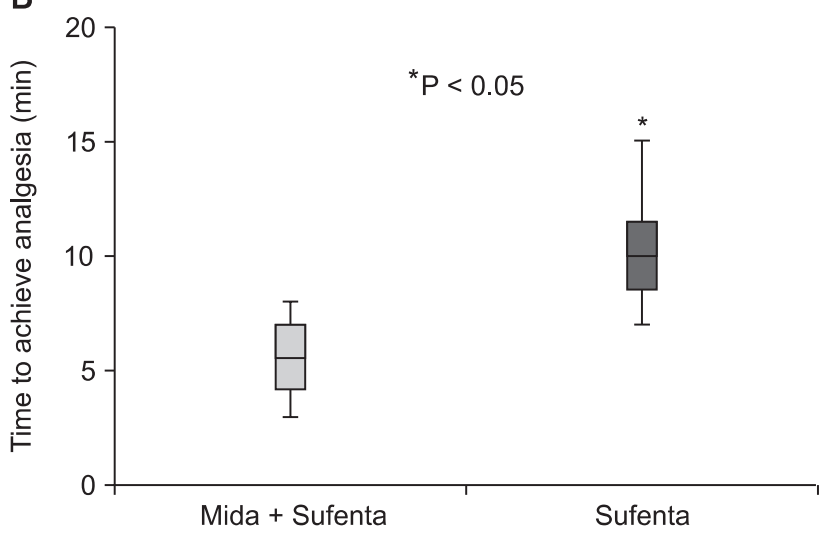

Fig. 1. Hemodynamic changes in two groups of study after intrathecal injection of drugs isdepicted in (A) (MAP: mean arteria blood pressure). The data is expressed as the mean $\pm \mathrm{SD}$. $* \mathrm{P}<0.05$ Midazolam versus the sufentanil group by ANOVA (A). Comparison of time to achieve sensory analgesia (block of pain) in intrathecal injection of Sufentanil alone (control) and sufentanil adjunct to Midazolam. Box-whiskers graph shows median and minimum and maximum. $* \mathrm{P}<0.05$ Midazolam versus thesufentanil group by t-test (B).

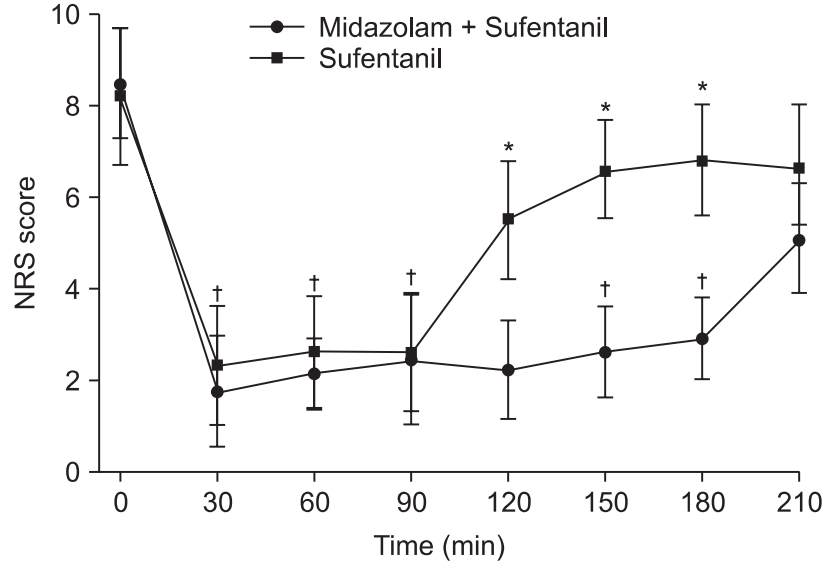

Fig. 2. Numeric rating scale (NRS) score during time points after labor analgesia in two groups of study.The data is expressed as the mean $\pm \mathrm{SD} .{ }^{*} \mathrm{P}<0.05$ Midazolam versus the sufentanil group by ANOVA test. ${ }^{\dagger} \mathrm{P}<0.05$ versus the 0 time point by ANOVA test.

\section{Duration of analgesia}

The time to achieve sensory analgesia was $6.78 \pm 1.20 \mathrm{~min}$ (mean \pm standard deviation) in the experimental group (combination of midazolam and sufentanil), and $9.66 \pm 2.24 \mathrm{~min}$ in the control group (sufentanil); the difference was significant (P $=0.001$ ) (Fig. 2). The duration of analgesia was $92 \pm 12.7 \mathrm{~min}$ in the sufentanil group and $185.2 \pm 15.2 \mathrm{~min}$ in the midazolam plus sufentanil group; the difference was significant $(\mathrm{P}=0.002)$.

NRS

The baseline NRS scores were not significantly different be- tween the two groups $(\mathrm{P}=0.6)$. The mean NRS score decreased significantly at $30 \mathrm{~min}$ post-intrathecal injection compared with the baseline NRS in the midazolam $(\mathrm{P}=0.01)$ and sufentanil ( $\mathrm{P}$ $=0.02$ ) groups (Fig. 2). The two groups were then subjected to ANOVA of the stages of analgesia at different time points; the difference within each group was significant. The stages of complete analgesia at the same time point also differed significantly between the two groups. The NRS scores were not significantly different at $30(\mathrm{P}=0.33), 60(\mathrm{P}=0.25)$, and $90(\mathrm{P}=0.35) \mathrm{min}$ in the midazolam and sufentanil groups. However, the NRS scores were significantly lower in the midazolam group than in the sufentanil group at $120(\mathrm{P}=0.01), 150(\mathrm{P}=0.0014)$, and 180 $(P=0.001)$ min. Regression analysis showed that the estimated relative risk postinjection (intrathecal midazolam in the experimental group) was significant $(\mathrm{RR}=1.92,95 \% \mathrm{CI}=1.23-2.99, \mathrm{P}$ $=0.03$ ).

\section{Discussion}

Clinicians have long been disinclined to use intrathecal midazolam for labor pain for fear of its adverse effects on labor muscle force, prolongation of the labor phases, and Apgar scores. Parturients vary tremendously in their responses to labor pain analgesics. Whereas multiple adjuvant agents have been investigated to prolong analgesia (from intrathecal opioids to local anesthetics), none are widely used because of their side effects. Recently, intrathecal injection of adjunct midazolam has gained much attention [12]. In our study, intrathecal midazolam as an adjunct to sufentanil significantly increased the quality and duration of analgesia as measured by the NRS score. Adjunct midazolam and sufentanil also diminished the onset of the block. 
The primary outcome of our study was the duration of analgesia, which was $\sim 4 \mathrm{~h}$ in the experimental group. Sufentanil alone provides analgesia for at most $\sim 120 \mathrm{~min}$. A combination of intrathecal bupivacaine, fentanyl, and morphine provided a $4 \mathrm{~h}$ window of acceptable analgesia for parturients without complications, which is not markedly different from the effects of midazolam and sufentanil in our study [13]. A combination of intrathecal bupivacaine and midazolam may last longer than $4 \mathrm{~h}$, but its disadvantage is the induction of motor blockade [14]. The time to achieve maximum blockade was similar when midazolam was added to the baseline analgesics; however, the time to the first rescue analgesic when using midazolam added to bupivacaine [15] or sufentanil (our study) was much longer than that of bupivacaine or sufentanil alone.

The molecular targets responsible for the specific analgesic activity of intrathecal midazolam remain to be elucidated. Although major progress has been made, the mechanism of intrathecal midazolam remains unclear. Midazolam is a benzodiazepine that acts centrally on gamma-aminobutyric acid type A $\left(\mathrm{GABA}_{\mathrm{A}}\right)$ receptors as a hypnotic drug. Thus, interest in the mechanisms responsible for its remarkable neuroaxial analgesic effects has increased. Further research has shown that activation of GABA receptors in the posterior horn regulates [16] pre- and postsynaptic a-amino-3-hydroxy-5-methyl-4-isoxazoleproionic acid receptor expression and function in the spinal column [17]. These receptors inhibit excitatory postsynaptic currents in postsynaptic $\mathrm{C}$ and A fiber neurons in the spinal column, which subsequently decrease posterior horn neuronal activation. In the presence of intrathecal midazolam, endogenous opioid neurotransmitters are released to activate delta receptors [18] and decrease nociception receptor activation [19]. This may partially explain the mechanism of benzodiazepine-induced spinal analgesia. In addition, the analgesic effect of intrathecal midazolam may be induced by direct action on benzodiazepine receptors in the spinal cord [20]. It has been proven that analgesia is mediated through both GABA receptors at local circuate interneurons in the posterior horn and a decrease in pain input to the rostral central nervous system structures, such as the thalamus, brain stem, and hypothalamus, which in turn influence the cortical and limbic brain structures necessary for conscious perception and appreciation of pain [21]. The sedative and amnestic effects of midazolam may also be involved in its analgesic effects.

Adjunct intrathecal midazolam did not exhibit significant effects on hemodynamic variables. We showed that adjunct intrathecal midazolam can potentially provide more prolonged analgesia than opioids alone while inhibiting their adverse effects, such as nausea and vomiting (our results). The molecular basis of the specific antiemetic activity of intrathecal midazolam remains to be elucidated.

Side effects, such as decreases in the Apgar score, were not significantly higher when midazolam was added to sufentanil. Intravascular midazolam can reach the placenta and induce a decrease in the Apgar score, whereas intrathecal midazolam produces an inconsequential plasma midazolam level that does not decrease the Apgar score, as reported previously [22].

A limitation of our study is the lack of consideration of intrathecal midazolam toxicity [23]. However, none of our patients showed signs of neurotoxicity. Numerous human and animal studies emphasize the safety of intrathecal midazolam [24,25]. These studies identified a dose of midazolam that is not associated with neurotoxicity at either a clinical or histopathological level. Unlike animal studies [26,27], the results of human studies vary tremendously. This may be due to by the complexity of such research, in which several variables change simultaneously. In light of these facts, we examined our parturients with extreme caution in terms of the development of any neurological sequelae (motor or sensory). We followed our parturients for 48 $h$ postoperatively and advised them to return if any neurological signs developed in the subsequent 2 months. The lack of neurological symptoms in our parturients does not definitively rule out the possibility of long-term neurotoxicity of intrathecal midazolam administration in humans, so future long-term followup studies of parturients are warranted.

In conclusion, intrathecal midazolam as an adjunct to an opioid can significantly enhance analgesia for labor pain. This improvement in the analgesic effect is not accompanied by significant side effects, and provides safe anesthesia to the parturient. Providing high-quality analgesia to females in labor in rural or small urban centers is of paramount importance. Anesthesiologists practicing modern anesthesia in small-hospital settings may find a single-dose intrathecal injection of midazolam to be a useful alternative to parenteral or epidural analgesia.

\section{References}

1. Minty RG, Kelly L, Minty A, Hammett DC. Single-dose intrathecal analgesia to control labor pain: is it a useful alternative to epidural analgesia? Can Fam Physician 2007; 53: 437-42.

2. Cambic CR, Wong CA. Labour analgesia and obstetric outcomes. Br J Anaesth 2010; 105 Suppl 1: i50-60.

3. Lee BB, Ngan Kee WD, Hung VY, Wong EL. Combined spinal-epidural analgesia in labour: comparison of two doses of intrathecal bupivacaine with fentanyl. Br J Anaesth 1999; 83: 868-71. 
4. Vasudevan A, Snowman CE, Sundar S, Sarge TW, Hess PE. Intrathecal morphine reduces breakthrough pain during labour epidural analgesia. Br J Anaesth 2007; 98: 241-5.

5. Yaksh TL, Allen JW. The use of intrathecal midazolam in humans: a case study of process. Anesth Analg 2004; 98: 1536-45.

6. Kim MH, Lee YM. Intrathecal midazolam increases the analgesic effects of spinal blockade with bupivacaine in parturients undergoing haemorrhoidectomy. Br J Anaesth 2001; 86: 77-9.

7. Yaksh TL, Allen JW. Preclinical insights into the implementation of intrathecal midazolam in humans: a cautionary tale. Anesth Analg 2004; 98: 1509-11.

8. Prakash S, Joshi N, Gogia AR, Prakash S, Singh R. Analgesic efficacy of two doses of intrathecal midazolam with bupivacaine in parturients undergoing cesarean delivery. Reg Anesth Pain Med 2006; 31: 221-6.

9. Tucker AP, Lai C, Nadeson R, Goodchild CS. Intrathecal midazolam I: a cohort study investigating safety. Anesth Analg 2004; 98: 1512-20.

10. Tucker AP, Mezzatesta J, Nadeson R, Goodchild CS. Intrathecal midazolam II: combination with intrathecal fentanyl for labor pain. Anesth Analg 2004; 98: 1521-7.

11. Melzack R, Kinch R, Dobkin P, Lebrun M, Taenzer P. Severity of labour pain: influence of physical as well as psychologic variables. Can Med Assoc J 1984; 130: 579-84.

12. Kim MH, Lee YM. Intrathecal midazolam increases the analgesic effects of spinal blockade with bupivacaine in parturients undergoing haemorrhoidectomy. Br J Anaesth 2001; 86: 77-9.

13. Minty RG, Kelly L, Minty A, Hammett DC. Single-dose intrathecal analgesia to control labour pain: is it a useful alternative to epidural analgesia? Can Fam Physician 2007; 53: 437-42.

14. Wu YW, Shiau JM, Hong CC, Hung CP, Lu HF, Tseng CC. Intrathecal midazolam combined with low-dose bupivacaine improves postoperative recovery in diabetic mellitus parturients undergoing foot debridement. Acta Anaesthesiol Taiwan 2005; 43: 129-34.

15. Agrawal N, Usmani A, Sehgal R, Kumar R, Bhadoria P. Effect of intrathecal midazolam bupivacaine combination on post operative analgesia. Indian J Anesthesia 2005; 49: 37-9.

16. Kohno T, Wakai A, Ataka T, Ikoma M, Yamakura T, Baba H. Actions of midazolam on excitatory transmission in dorsal horn neurons of adult rat spinal cord. Anesthesiology 2006; 104: 338-43.

17. Lim J, Lim G, Sung B, Wang S, Mao J. Intrathecal midazolam regulates spinal AMPA receptor expression and function after nerve injury in rats. Brain Res 2006; 1123: 80-8.

18. Cox RF, Collins MA. The effects of benzodiazepines on human opioid receptor binding and function. Anesth Analg 2001; 93: 354-8.

19. Goodchild GS, Guo Z, Musgreave A, Gent JP. Antinociception by intrathecal midazolam involves endogenous neurotransmitters acting at spinal cord delta opioid receptors. Br J Anaesth 1996; 77: 758-63.

20. Crawford ME, Jensen FM, Toftdahl DB, Madsen JB. Direct spinal effect of intrathecal and extradural midazolam on visceral noxious stimulation in rabbits. Br J Anaesth 1993; 70: 642-6.

21. Valentine JM, Lyons G, Bellamy MC. The effect of intrathecal midazolam on post-operative pain. Eur J Anaesthesiol 1996; 13: 589-93.

22. Frölich MA, Burchfield DJ, Euliano TY, Caton D. A single dose of fentanyl and midazolam prior to Cesarean section has no adverse neonatal effects. Can J Anaesth 2006; 53: 79-85.

23. Malinovsky JM, Cozian A, Lepage JY, Mussini JM, Pinaud M, Souron R. Ketamine and midazolam neurotoxicity in the rabbit. Anesthesiology 1991; 75: 91-7.

24. Safari F, Dabbagh A, Sharifnia M. The effect of adjuvant midazolam compared with fentanyl on the duration of spinal anesthesia with $0.5 \%$ bupivacaine in opium abusers. Korean J Anesthesiol 2012; 63: 521-6.

25. Canavero S, Bonicalzi V, Clemente M. No neurotoxicity from long-term ( $>5$ years) intrathecal infusion of midazolam in humans. J Pain Symptom Manage 2006; 32: 1-3.

26. Erdine S, Yücel A, Ozyalçin S, Ozyuvaci E, Talu GK, Ahiskali B, et al. Neurotoxicity of midazolam in the rabbit. Pain 1999; 80: 419-23.

27. Malinovsky JM, Cozian A, Lepage JY, Mussini JM, Pinaud M, Souron R. Ketamine and midazolam neurotoxicity in the rabbit. Anesthesiology 1991; 75: 91-7. 